\title{
Retinal involvement in acute thrombotic thrombocytopenic purpura: a case report
}

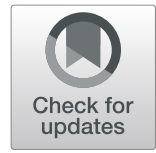

\author{
A. G. N. M. K. Bandara * and Anne Thushara Matthias
}

\begin{abstract}
Background: Thrombotic thrombocytopenic purpura (TTP) is a life-threatening hematological condition associated with deficiency in ADAMTS13. Ocular manifestations associated with TTP are uncommon.

Case presentation: Here we report a case where a 44 year old female patient with a history of symptomatic anemia and cotton wool appearance in retina during ophthalmological examination and subsequently, she was diagnosed to have TTP. The proper management with Therapeutic Plasma Exchange (TPE) and IV methylprednisolone improved the condition of the patient markedly.

Conclusion: It concludes that even though the presence of cotton wool appearance in retina is a nonspecific sign it needs to be properly evaluated as there can be underlying serious illnesses as in our patient. Cotton wool spots can be an early sign of underlying retinal compromise and it should be identified early.
\end{abstract}

Keywords: Cotton wool spots in retina, Thrombotic Thrombocytopenic Purpura, Therapeutic Plasma Exchange, Case report

\section{Background}

Thrombotic Thrombocytopenic Purpura (TTP) is a rare, life threatening hematological disease characterized by severe thrombocytopenia, microangiopathic hemolytic anemia, and organ ischemia associated with microvascular platelet rich thrombi. The brain is the most affected organ due to ischemia in TTP as $60 \%$ of patients have neurological symptoms at presentation, which range from headache to stroke and coma [1]. Ocular manifestations related to TTP are usually uncommon and underestimated due to the fact that they are mainly detectable in the preterminal stage of TTP [2]. Ocular involvement reported are serous macular detachments, choriocapillaris occlusion due to fibrin-platelet thrombi, retinal or vitreous hemorrhages, optic disc edema, neovascularization of the disc, central retinal vein occlusion, anisocoria, diplopia and homonymous hemianopia [3]. According to the published literature this was reported

* Correspondence: nimmi.madu7@gmail.com

Colombo South Teaching Hospital, Kalubowila, Dehiwala, Western Province, Sri Lanka

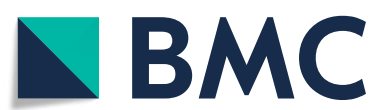

only in 14-20\% of patients with TTP [4]. Here we report a case of TTP where the patient presents with a nonspecific headache and ocular manifestation of cotton wool spot in right fundus without any visual disturbances.

\section{Case presentation}

A 44 -year-old previously healthy female was admitted with a history of generalized body weakness, malaise, exertional shortness of breath for one-week and episodic nonspecific headache for last one-month duration. There was no fever, urinary, bowel, respiratory symptoms or visual disturbances. Despite blood transfusion during her second pregnancy due to low Haemoglobin, her both pregnancies were uneventful. There were no suggestive features of autoimmune diseases or no bleeding manifestations. She had no significant past medical history or family history.

On hospital admission, her Glasgow Coma Scale (GCS) was 15 and she was severely pale with mild tinge of icterus. No generalize lymphadenopathy or petechial rashes. Abdominal examination revealed mild hepatomegaly

(c) The Author(s). 2020 Open Access This article is licensed under a Creative Commons Attribution 4.0 International License, which permits use, sharing, adaptation, distribution and reproduction in any medium or format, as long as you give appropriate credit to the original author(s) and the source, provide a link to the Creative Commons licence, and indicate if changes were made. The images or other third party material in this article are included in the article's Creative Commons licence, unless indicated otherwise in a credit line to the material. If material is not included in the article's Creative Commons licence and your intended use is not permitted by statutory regulation or exceeds the permitted use, you will need to obtain permission directly from the copyright holder. To view a copy of this licence, visit http://creativecommons.org/licenses/by/4.0/ The Creative Commons Public Domain Dedication waiver (http://creativecommons.org/publicdomain/zero/1.0/) applies to the data made available in this article, unless otherwise stated in a credit line to the data. 
without splenomegaly. Other than cotton wool appearance in the right fundus (Fig. 1), rest of the neurological examination (including left fundus (Fig. 2), visual acuity, visual field and pupillary reaction) was uneventful. Her blood pressure was $120 / 80 \mathrm{mmHg}$ and pulse rate was 80 / min. Respiratory examination was unremarkable. Random blood sugar was $123 \mathrm{mg} / \mathrm{dl}$.

Her results of investigations showed WBC $7.84 \times 10^{3} /$ $\mu \mathrm{L}, \mathrm{Hb} 6.7 \mathrm{mg} / \mathrm{dl}$, platelet $23 \times 10^{3} / \mu \mathrm{L}, \mathrm{MCV} 98.3 \mathrm{fL}$, RDW 21.7\%, blood picture suggestive of Micro angiopathic hemolytic anemia, retic count 13\%, DAT negative, LDH $817 \mathrm{U} / \mathrm{L}$, serum creatinine $56.6 \mu \mathrm{mol} / \mathrm{L}, \mathrm{CRP}<5$ mg/L, urine HCG negative, AST 34 U/L, Indirect bilirubin $29 \mu \mathrm{mol} / \mathrm{L}$, INR 0.96, APTT $27 \mathrm{~s}$, Fibrinogen $2.5 \mu \mathrm{mol} / \mathrm{L}$, Thrombin time16.3 s, CPK $102 \mathrm{U} / \mathrm{L}$, ESR 12, USS abdomen grade II fatty liver only, CXR and 2D Echo normal. ANA, VDRL, retroviral and other viral studies were negative.

According to the above investigation findings, she was found to have severe thrombocytopenia and micro angiopathic hemolytic anemia, which are the two key diagnosis criteria of TTP. With the other supportive investigations, the diagnosis was made as TTP.

She was managed with urgent TPE and intravenous methylprednisolone $1 \mathrm{~g} /$ day for 3 days initially and then converted to oral prednisolone $1 \mathrm{mg} / \mathrm{kg} /$ day. Her platelet count was markedly improved, and it was more than 150,000 after 3rd cycle of plasma exchange. She was given blood transfusion and her symptoms were improved. She was discharged with oral prednisolone and followed up at hematology clinic.

\section{Discussion}

Cotton wool spots can be a sign of serious systemic disease. The presence of cotton wool spots in the retina is a nonspecific finding as there are many common causes such as Diabetes, Hypertension, Retinal vessel occlusion, Collagen-vascular diseases, and AIDS retinopathy [5].

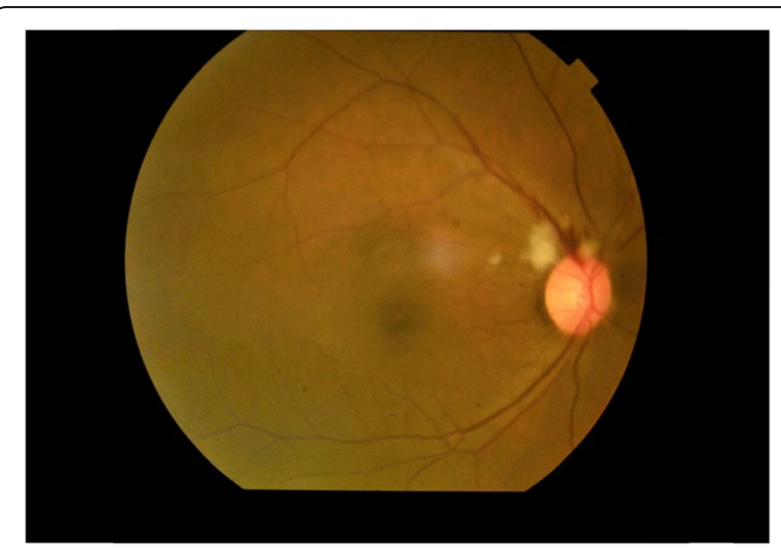

Fig. 1 Cotton wool appearance in the Right Fundus

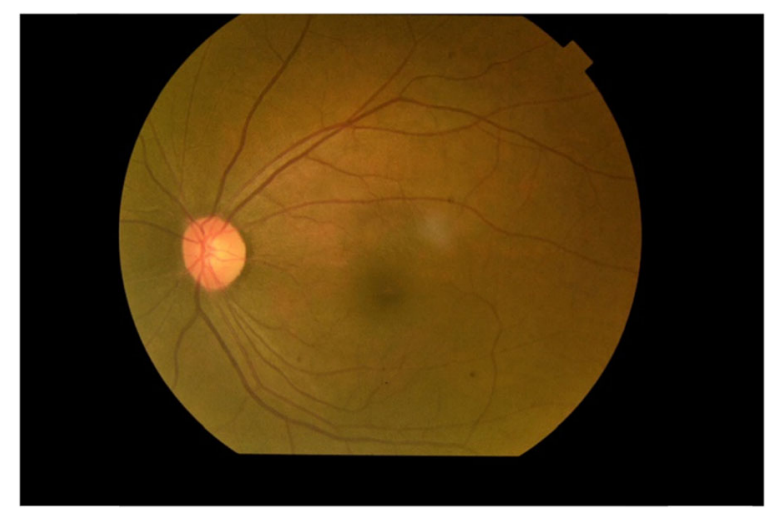

Fig. 2 Normal Left Fundus

The initial evaluation of cotton wool spots include blood pressure measurement, complete blood count with platelets and evaluation for diabetes. In our patient the blood pressure was normal throughout the hospital stay hence cotton wool spots are unlikely to be related to it. In this patient, there was TTP accounting for the cotton wool spots. According to the available clinical and laboratory investigations in this case, we could exclude most of the common causes of cotton wool spots in retina. This revealed the fact that the particular retinal condition was associated with TTP, which was diagnosed based on the other clinical criteria of the patient. If visual symptoms and signs are not paid attention to in evaluating the patient can have devastating consequences such as visual loss, ischemic or hemorrhagic stroke, seizures, coma or even death [6].

Ocular manifestations of TTP are rare and they depend on which blood vessels are damaged. Cotton wool spots in association with TTP to our knowledge has not been reported before. According to Percival's clinical classification of ophthalmologic manifestations, retinal ischemia characterized by cotton wool appearance in this patient categorized as a ocular sign of systemic disorders caused by thrombotic microangiopathy [4]. However, the most common ocular manifestation in TTP is serous macular detachments [7]. Other ophthalmic manifestations include, choriocapillaris occlusion due to fibrin-platelet thrombi, retinal or vitreous hemorrhages, optic disc edema, neovascularization of the disc, central retinal vein occlusion, anisocoria, diplopia and homonymous hemianopia [3].

The onset of ophthalmological manifestations in TTP can either be early or late in the disease process. Ong et al. identified that retinal conditions and visual disturbances can be early signs of underlying systemic microangiopathy while Lambert et al. identified them to occur later in the disease process $[8,9]$.

Depending on the affected organ symptoms of TTP can be vary. It may include acute vision loss due to 
retinal pathology, blurring of vison due to papilledema or diplopia if cranial nerves are affected [10]. With the disease progression, there will be suggestive ocular symptoms of systemic damage including hypertensive retinopathy, palpebral purpura or swelling, chemosis, subconjunctival bleeding, scleral jaundice and finally retinal bleeding [4]. Therefore possibility of TTP should be considered in patients who present with vaso-occlusive disease of the retina. Further research revealed that fundus findings may be a prognostic factor in TTP [11].

Fever, thrombocytopenia, microangiopathic hemolytic anemia, neurological symptoms, and renal insufficiency were the pentad used to define TTP historically. However, this became obsolete as only less than $10 \%$ of patients with an acute TTP were presented with these five symptoms. Currently severe thrombocytopenia (typically $<30 \times 10^{9} / \mathrm{L}$ ) and microangiopathic hemolytic anemia are identified as most constant and common signs of acute TTP [1]. Apart from these two signs, this patient presented with uncommon retinal involvement of cotton wool spots in right fundus.

Early detection and appropriate therapeutic management would reduce the mortality rate of TTP up to 10 to $20 \%[12,13]$. Therefore, patients need to be screened for the ocular manifestations as such conditions can be an early sign of TTP [8]. TPE with replacement of plasma remains as the core of current management of TTP [14]. The clinical and hematological parameters of this patient were markedly improved following TPE and high dose of steroids.

\section{Conclusions}

Cotton wool spots can be a sign of serious systemic disease and warrant further evaluation in certain clinical scenarios, as in this patient, a life-threatening illness was discovered. Such retinal involvement can be occurred in the course of TTP without any significant symptoms. Complete hematologic and metabolic workup should be initiated promptly due to early treatment with TPE reduces mortality rate from this rapidly fatal condition. This case report revealed that examination of fundus and vision is of paramount clinical important because TTP can lead to fatal ocular manifestations which could be detected as an early sign of the disease. Although TTP-HUS is a rare disorder, it should be considered in patients who present with vaso-occlusive disease of the retina. The mortality rate of this condition can be very high without urgent intervention, ophthalmologists may play a key role in its timely diagnosis if patients with TTP present with ophthalmological signs and symptoms.

\section{Abbreviations}

AIDS: Acquired Immune Deficiency Syndrome; GCS: Glasgow Coma Scale; TTP: Thrombotic Thrombocytopenic Purpura; TPE: Therapeutic Plasma Exchange; WBC: White Cell Count; MCV: Mean Corpuscular Volume;
RDW: Red Cell distribution Width; DAT: Direct Antiglobulin Test; LDH: Lactate Dehydrogenase; CRP: C Reactive Protein; HCG: Human Chorionic Gonadotropin; AST: Aspartate Aminotransferase; INR: International Normalized Ratio; APTT: Activated Partial Thromboplastin Time; CPK: Creatine Phosphokinase; ESR: Erythrocyte Sedimentation Rate; USS: Ultrasound Scan; CXR: Chest X-ray; ANA: Anti-Nuclear Antibody; VDRL: Venereal Disease research Laboratory

\section{Acknowledgements}

The authors would like to thank the patients and her family. We also grateful to Dr. B. Fernandopulle, Dr. C. Munasinghe and Dr. V. Gurusamy of Colombo South Teaching Hospital for their guidance.

\section{Authors' contributions}

A.G.N.M.K.B collected the clinical information of the patient, reviewed literature and drafted the manuscript. A.T.M drafted, reviewed and edited the manuscript. All authors have read and approved the final manuscript. Both ATM and AGNKB were involved in the management of the patient.

Funding

None.

Availability of data and materials

All data gathered during this study are included in this manuscript.

Ethics approval and consent to participate

Not applicable.

\section{Consent for publication}

Written informed consent of the patient was obtained for the publication of clinical data and images included in this case report.

\section{Competing interests}

The authors declare that they have no competing interests.

Received: 22 June 2020 Accepted: 5 November 2020

Published online: 19 November 2020

References

1. Joly BS, Coppo P, Veyradier A. Thrombotic thrombocytopenic purpura. Blood. 2017;129(21):2836-46 The Journal of the American Society of Hematology.

2. Benson DO, Fitzgibbons JF, Goodnight SH. The visual system in thrombotic thrombocytopenic purpura. Ann Ophthalmol. 1980;12(4):413-7.

3. Percival SP. Ocular findings in thrombotic thrombocytopenic purpura (Moschcowitz's disease). Br J Ophthalmol. 1970;54(2):73.

4. Bobbio-Pallavicini E, Porta C, Brocchieri A, Saporiti A, Tacconi F. Ocular involvement in acute thrombotic thrombocytopenic purpura. Haematologica. 1995;80(2):194-5.

5. Doan, A., Farjo, A., 2005. TTP-HUS: 29-year-old male with HA, hematuria, and visual obscurations. [Online] Available at: http://www.EyeRounds.org/cases/ case1.htm (Accessed on 24 Apr 2020).

6. Wun, T., 2019. Thrombotic Thrombocytopenic Purpura (TTP): practice essentials, background, pathophysiology. [Online] Emedicine.medscape.com. Available at: https://emedicine.medscape.com/article/206598-overview\#a6 (Accessed 4 May 2020).

7. Raabe J, Bhat N, Bindiganavile SH, Lee AG. Ophthalmologic manifestations of Thrombotic Thrombocytopenic Purpura (TTP): American Academy of Ophthalmology; 2020. [Online] Available at https://eyewiki.aao.org/ Ophthalmologic_Manifestations_of_Thrombotic_Thrombocytopenic_ Purpura_(TTP) (Accessed 28 Jul 2020).

8. Ong T, Nolan W, Jagger J. Purtscher-like retinopathy as an initial presentation of thrombotic thrombocytopenic purpura: a case report. Eye. 2005;19(3):359-61.

9. Lambert SR, High KA, Cotlier E, Benz EJ. Serous retinal detachments in thrombotic thrombocytopenic purpura. Arch Ophthalmol. 1985;103(8):1172-4.

10. Vadhar, N. \& Williams, A., 2014. June 2014 wills eye resident case series diagnosis \& discussion. reviewofophthalmology.com. [Online] Available at: https://www.reviewofophthalmology.com/article/june-2014-wills-eyeresident-case-series-diagnosis\%2D\%2Ddiscussion (Accessed 28 Jul 2020). 
11. Douzinas EE, Markakis KOSTANTINOS, Karabinis ANDREAS, Mandalaki TITIKA, Bilalis DIMITRIOS, Fessas PHAEDON. Early plasmapheresis in patients with thrombotic thrombocytopenic purpura. Crit Care Med. 1992;20(1):57-61.

12. Zheng $X L$, Kaufman RM, Goodnough LT, Sadler JE. Effect of plasma exchange on plasma ADAMTS13 metalloprotease activity, inhibitor level, and clinical outcome in patients with idiopathic and nonidiopathic thrombotic thrombocytopenic purpura. Blood. 2004;103(11):4043-9.

13. Sadler JE. What's new in the diagnosis and pathophysiology of thrombotic thrombocytopenic purpura. Hematol 2014, the American Society of Hematology Education Program Book. 2015;2015(1):631-6.

14. Rock GA, Shumak KH, Buskard NA, et al. Canadian apheresis study group. Comparison of plasma exchange with plasma infusion in the treatment of thrombotic thrombocytopenic purpura. N Engl J Med. 1991;325(6):393-7.

\section{Publisher's Note}

Springer Nature remains neutral with regard to jurisdictional claims in published maps and institutional affiliations.

Ready to submit your research? Choose BMC and benefit from:

- fast, convenient online submission

- thorough peer review by experienced researchers in your field

- rapid publication on acceptance

- support for research data, including large and complex data types

- gold Open Access which fosters wider collaboration and increased citations

- maximum visibility for your research: over $100 \mathrm{M}$ website views per year

At $\mathrm{BMC}$, research is always in progress.

Learn more biomedcentral.com/submissions 